\title{
Linkage of Marie-Unna hypotrichosis locus to chromosome 8p21 and exclusion of 10 genes including the hairless gene by mutation analysis
}

\author{
Pascal Lefevre ${ }^{1}$, Ariane Rochat ${ }^{2}$, Christine Bodemer $^{3}$, Pierre Vabres ${ }^{3}$, Yann Barrandon ${ }^{2}$, \\ Yves de Prost $^{3}$, Chad Garner ${ }^{1}$ and Alain Hovnanian ${ }^{1}$
}

${ }^{1}$ The Wellcome Trust Centre for Human Genetics, University of Oxford, UK; ${ }^{2}$ Department of Biology, Ecole Normale
Supérieure; ${ }^{3}$ Department of Dermatology, Hôpital Necker-Enfants malades, Paris, France

Marie-Unna hypotrichosis (MU) is a rare autosomal dominant congenital alopecia characterised by progressive hair loss starting in early childhood, often aggravated at puberty and leading to scarring alopecia of variable severity. We have studied three multigeneration families of Belgian, British and French descent. The human genome was screened with microsatellite markers spaced at 10-cM intervals and significant evidence for linkage to the disease was observed on chromosome 8p21, with a maximum two-point lod score of $\mathbf{8 . 2 6}$ for D8S1786 at a recombination fraction of 0. Recombinants narrowed the region of interest to a genetic interval of about $12 \mathrm{cM}$ flanked by markers D8S280 and D8S1839. This interval contains the hairless gene which is mutated in autosomal recessive congenital atrichia. Sequencing of the entire coding region and intronic splice sites of the hairless gene in these three families and in two unrelated familial cases revealed several polymorphic changes but failed to identify causative mutations. Nine other genes located within this region and expressed in skin were also excluded by mutation analysis. Together with a recent linkage study performed in a Dutch and a British family by van Steensel et al these results provide evidence for the presence of a gene distinct from hairless in chromosomal region 8p21 playing an important role in hair follicle biology. European Journal of Human Genetics (2000) 8, 273-279.

Keywords: Marie-Unna hypotrichosis; congenital alopecia; genetic linkage; chromosome 8p21; hairless gene

\section{Introduction}

Hereditary hypotrichosis of Marie Unna is a rare autosomal dominant congenital hair disorder (Mendelian Inheritance in Man no 146550) characterised by abnormal hair since or soon after birth, with progressive hair loss leading to various degrees of alopecia in adults. The disease was first described in 1925 by Marie Unna in a large North German family. ${ }^{1}$ Since then, several cases have been reported. ${ }^{2-6}$ Affected individuals are usually born with little or no hair, and coarse twisted hair grows on the scalp in early childhood. With the approach of puberty, the hair is progressively lost from the

Correspondence: Dr Alain Hovnanian, The Wellcome Trust Centre for Human Genetics, University of Oxford, Roosevelt Drive, Headington, Oxford, OX3 7BN, UK. Tel: +44 1865 287511; Fax: +44 1865 287501; E-mail: alain.hovnanian@well.ox.ac.uk

Received 6 August 1999; revised 8 November 1999; accepted

16 November 1999 vertex and scalp margins resulting in scarring alopecia whose extent varies from a patchy pattern to complete baldness. Eyebrows, eyelashes and body hair are also markedly diminished or absent. There are no other ectodermal abnormalities. The disease affects both males and females, although the extent of baldness is usually greater in the former. Histological examination shows a marked reduction of hair follicles which are often atrophic. Proliferative outgrowths from hair follicles into the surrounding dermis have been reported, as well as outer root sheath bulging. ${ }^{1,2,4,5}$ Light microscopy of affected hair shows coarse, flattened and irregularly twisted hair, with longitudinal ridges upon scanning electron microscopy examination. Electron microscopic studies show longitudinal fractures within the cuticular, cortical and medullary cells of hair ${ }^{3,5}$ These clinical features and hair abnormalities clearly distinguish MU from other isolated autosomal dominant alopecia such as monilethrix and pili torti. They also suggest that genes controlling hair 
growth or encoding structural proteins of the hair shaft could be candidates for MU.

Hair formation and cycling is a complex process which involves a series of mesenchymal-epithelial interactions implicating many genes, a large number of which remain unidentified. ${ }^{7}$ Previous studies have provided evidence that fibroblast growth factors, bone morphogenetic proteins, Sonic hedgehog and members of the Wingless and Notch signalling pathways play an important role in the control of hair development. ${ }^{8-10}$ Recently, several genes have been implicated in different inherited alopecia in humans. Mutations in the hair cortex keratins $\mathrm{hHb} 6$ and $\mathrm{hHbl}$ on chromosome $12 \mathrm{q} 13$ cause monilethrix, a rare autosomal dominant congenital alopecia with variable expression. ${ }^{11}$ The human homologue of the mouse hairless gene located in 8p21-23 encodes a zinc-finger transcription factor which is mutated in autosomal recessive congenital atricia (MIM 203655). ${ }^{12-16}$ The human winged-helix-nude (W NH) gene on chromosome17 which codes for a transcription factor is deficient in recessive congenital al opecia with severe functional T-cell immunodeficiency. ${ }^{17}$ Mutations in the human homologue of mouse downless gene (dl) in 2q11-13 cause autosomal recessive and dominant hypohidrotic ectodermal dysplasia. ${ }^{18}$ Defective genes in $\mathrm{X}$-linked recessive diseases with congenital hypotrichosis include the EDA gene encoding a transmembrane protein in anhidrotic ectodermal dysplasia ${ }^{19}$ and the copper transporter ATP7A gene in Menkes disease. $^{20}$

In this article, we report the mapping of the MU locus to chromosome8p21 in three kindreds and exclude, by mutation analysis, the hairless gene and nine other genes mapping in this region as being the defective genes.

\section{Materials and methods \\ Family and controls}

Three families and two unrelated patients were studied.

Family F1 is a large French kindred of Belgian descent which is affected with MU through four generations. At birth, affected individuals had little or no scalp hair. During childhood, stiff coarse black hair developed on the scalp, and from about the age of puberty, was progressively lost mainly on the vertex and scalp margins. Extensive scarring alopecia was noted in some individuals (Figure1). Other patients had alopecia localised to the vertex only or had thinning of scalp hair which was coarse and irregular. Eyebrows, eyelashes, axillary, pubic and beard hair was reduced, sparse or absent. Light microscopy examination from hair of the scalp showed thickened, irregular and twisted hair. Histological examination of scalp biopsies showed a decreased number of hair follicles and marked bud-like outgrowths of basaloid cells from the outer root sheath in the dermis.

Family F2 is a three-generation French family in which affected individuals showed no hair or very little hair at birth and developed abnormal thick and coarse hair during

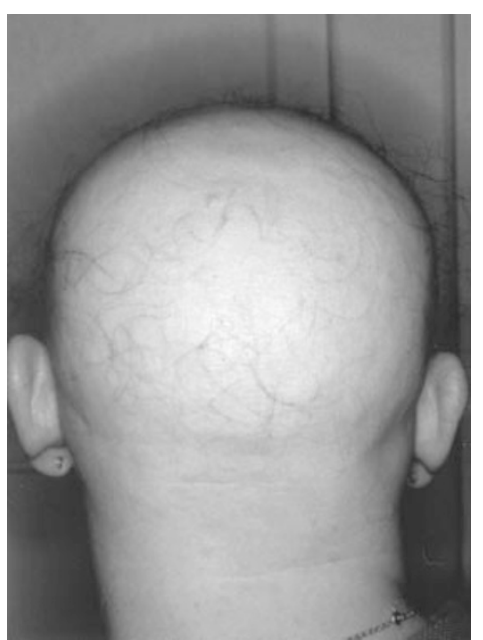

Figure 1 Almost complete scarring alopecia with very sparse hair in patientF1-10, age 46.

infancy. Subsequently, the hair was progressively lost in adulthood from the vertex of the scalp. As in family F1, a wide variation in the age of onset (from 20 to 40 years of age) and in the extent of hair loss was observed between affected members.

Family B1 is a four generation British family whose clinical characteristics have been described. ${ }^{6}$ Patients B. 2 and B. 3 are 53 and 47-year-old affected female individuals from two unrelated British families with MU through two and six generations, respectively. Genomic DNA was isolated from peripheral blood leukocytes collected in EDTA tubes. Samples were collected after informed consent was obtained from the subjects. The presence of rare nucleotide changes identified in the hairless gene was examined in 180 controls from Bel gium, in 50 controls from France and 50 controls from the UK.

\section{Genotyping}

The linkage mapping marker set 2 from ABI Perkin Elmer was used, with 400 fluorescent markers covering the genome at about 10-cM intervals. PCR primers were labelled with either 6-FAM, HEX or TET phosphoramidite (Applied Biosystem, Warrington, Cheshire, UK). Pooled products were run on a 373A sequencer (Applied Biosystems), followed by analysis with GENESCAN (version 2.0) and GENOTYPER (version 2.1) software. Refined screening of chromosomal region $8 \mathrm{p} 21$ showing positive lod scores was carried out using radioactive genotyping of microsatellite markers from the Généthon linkage map as described in ${ }^{21}$.

\section{Linkage analysis}

Autosomal dominant mode of inheritance with complete penetrance was assumed, with no phenocopies and a diseaseallele frequency of 0.0001 . Two-point lod scores were calculated using the MLINK and ILINK subroutines of the 
FASTLINK program. ${ }^{22}$ The effect of the marker allele frequencies on the lod scores was tested by simulation and determined to be insignificant. Therefore, the sample allele frequencies were used in the linkage analysis.

\section{Screening for mutations}

Skin biopsies were obtained from hairy scalp from patients F1-4, F1-5, F2-6 and from a healthy control. Hairs were microdissected and follicular keratinocytes were cultured as previously described. ${ }^{23}$ Total RNA was extracted from one $25 \mathrm{~cm}^{2}$ flask of cultured keratinocytes using TRIzol reagent (Life Technologies, Paisley, Renfrewshire, UK). Reverse transcription (RT) was performed as previously described. ${ }^{24}$ PCR amplification of reversed transcribed products (RT-PCR) was carried out using specific CDNA primers for the hairless gene (AF039196), calcineurin A catalytic subunit (S46622), homo sapiens SH3-containing adaptor molecule-1 (AF037261), KIAA0062 (D31887), EGR3 (730328), LOXL2 (U89942), human protein phosphatase 2A alpha subunit (M64929), guanosine-diphosphatase like protein (AF016032), FAK2 (L49207) and homo sapiens brain my047 protein (AF063605) (primers sequences are available, on request, from the authors). The conditions for PCR amplification were as described $\mathrm{in}^{24}$ with an annealing temperature of $60^{\circ} \mathrm{C}, 55^{\circ} \mathrm{C}$ or $50^{\circ} \mathrm{C}$. PCR amplification of the 18 coding exons of the human hairless gene was performed from genomic DNA using primer pairs and PCR conditions previously described. ${ }^{16}$ CSGE analysis was performed as described. ${ }^{25}$ PCR products showing abnormal migration pattern were purified and sequenced as previously described. ${ }^{24}$

\section{Results \\ Linkage of MUH to chromosomal region 8p21}

After a detectable cytogenetic rearrangement was excluded by karyotype analysis of metaphase chromosomes in an affected individual (F1.8), a genome-wide linkage study was initiated in 43 individuals of three families. Simultaneously several markers were tested from particular chromosomal regions where potential candidates' genes have been mapped. These include the typel and II hair keratin genes clusters in $17 q 12-q 23$ and $12 q 11-q 12$ respectively, ${ }^{26}$ the epidermal differentiation complex region in $1 q 21,{ }^{27}$ the desmocollin and desmoglein loci in $18 q 12.1^{28}$ and the human homologue of hairless in $8 p 21-22 .{ }^{13}$ Evidence of linkage was first provided by the 8p21 marker D8S1771 with a maximum pairwise lod score of 5.61 at $\theta=0.034$. We then studied eight additional microsatellite markers selected from the latest version of the Généthon human linkage map spanning $20 \mathrm{cM}$ around D8S1771. Lod scores exceeding 3 were observed for several markers, confirming linkage (Table1). A maximum lod score of 8.26 was obtained for marker D8S1786 at $\theta=0$. Haplotype analysis showed meiotic recombinations with markers telomeric to D8S282 in two affected individuals in family F1 (F1-4 and F1-5) and with markers centromeric to D8S1771 in an affected individual in family B1 (B1-4) and in a healthy individual in family F2

Table 1 Two-point lod scores between MU and chromosome 8p microsatellite markers

\begin{tabular}{|c|c|c|c|c|c|c|c|c|}
\hline \multirow[b]{2}{*}{ Marker } & \multirow{2}{*}{$\begin{array}{l}\text { Genetic } \\
\text { distance }^{a} \\
\text { (cM) }\end{array}$} & \multicolumn{5}{|c|}{ Lod scores at $\theta=$} & \multirow[b]{2}{*}{$Z_{\max }$} & \multirow[b]{2}{*}{$\theta_{\max }$} \\
\hline & & 0.000 & 0.050 & 0.100 & 0.200 & 0.300 & & \\
\hline D8S277 & 19 & $-\infty$ & 0.35 & 1.37 & 1.83 & 1.54 & 1.83 & 0.197 \\
\hline D8S549 & 9.6 & $-\infty$ & 0.52 & 1.08 & 1.24 & 0.96 & 1.26 & 0.173 \\
\hline D8S258 & 0 & $-\infty$ & 0.87 & 0.97 & 0.85 & 0.59 & 0.98 & 0.107 \\
\hline D8S280 & 1.3 & $-\infty$ & 2.99 & 2.82 & 2.15 & 1.33 & 2.99 & 0.048 \\
\hline D8S282 & 2.5 & 2.38 & 2.12 & 1.85 & 1.30 & 0.76 & 2.38 & $\varangle 0.001$ \\
\hline D8S1786 & 0.8 & 8.26 & 7.57 & 6.86 & 5.31 & 3.60 & 8.25 & $\varangle 0.001$ \\
\hline D8S1752 & 2 & 6.45 & 5.90 & 5.33 & 4.10 & 2.75 & 6.44 & $\varangle 0.001$ \\
\hline D8S1739 & 2.7 & 4.40 & 3.97 & 3.52 & 2.59 & 1.64 & 4.40 & $\varangle 0.001$ \\
\hline D8S1771 & 3.3 & 3.49 & 5.58 & 5.24 & 4.15 & 2.80 & 5.61 & 0.034 \\
\hline D8S1839 & 6.5 & $-\infty$ & 2.76 & 2.67 & 2.14 & 1.41 & 2.76 & 0.057 \\
\hline D8S1810 & 11.5 & $-\infty$ & 0.37 & 1.12 & 1.37 & 1.05 & 1.38 & 0.178 \\
\hline D8S285 & & $-\infty$ & 0.07 & 0.90 & 1.33 & 1.16 & 1.33 & 0.208 \\
\hline
\end{tabular}

aMeasured from the Généthon sex-average linkage map. 
(F2-5) (Figure2). These results mapped the disease locus between D8S280 and D8S1839 in a region estimated to be about $12 \mathrm{cM}$. No common haplotype suggestive of a founder effect was observed in affected individuals from the three families.

\section{Exclusion of the hairless gene}

This interval contains the hairless gene which is mutated in autosomal recessive congenital atrichia. ${ }^{12-16}$ This prompted us to screen this gene for mutations in patients with MU. The entire coding region of the hairless gene and intronic splice sites were sequenced from patients' genomic DNA from families F1, F2 and B1; and in two unrelated familial cases (B2 and $B 3$ ). In patients from families F1 and F2, the hairless CDNA was also sequenced from RT-PCR products obtained from total RNA of scalp keratinocytes. No causative mutation was identified in the human hairless gene and cDNA, although several polymorphisms, which were also found in controls were detected. Three rare single-nucleotide changes predicting amino-acid substitutions were identified: P62T $(\mathrm{CCC} \rightarrow$ ACC), C397Y $\quad($ TGC $\rightarrow$ TAC), and A576V $(\mathrm{GCC} \rightarrow \mathrm{GTC}$ ) and were also found in $0.4 \%, 10 \%$ and $0.5 \%$, respectively of the controls tested. Several additional nucleotide changes, some of which result in amino acid changes were also identified in comparison with the sequence deposited in Genbank (accession no. AF039196) ${ }^{13}$ but were in agreement with the cDNA sequence published in. ${ }^{16}$ Sequencing of the human hairless CDNA obtained from controls and patient cultured keratinocytes showed in addition to the normal sequence, transcripts lacking exon 17, as previously described in skin. ${ }^{16}$ Transcripts containing an additional CAG codon for glutamine preceding the first codon of exon 6 were also identified in controls and in patients, and were therefore not pathogenic.

\section{Exclusion of nine genes expressed in skin and mapping in the MUH region}

According to the human gene Map 99 (http://www.ncbi.nlm.nih.gov/genemap/), 32 genes and 92 ESTs map in the interval between markers D8S258 and D8S1820 which encompass the MU region. None of these genes and ESTs are obvious candidates or share sequence similarity with hairless. Nine genes whose transcripts had been isolated from skin cDNA libraries were selected for further investigation by mutation analysis (see Materials and methods). Transcripts of these genes were PCR amplified from reversed transcripted keratinocyte RNA (RT-PCR) in patients from families F1 and F2. Among these genes, RT-PCR products of the early growth response 3 gene (EGR3) which appeared as a potential candidate were fully sequenced. Transcripts of the eight other genes were screened for mutations using CSGE analysis. No mutation was identified in any of these nine genes.

\section{Discussion}

In this report we mapped by linkage analysis the disease locus for $\mathrm{MU}$ to a 12-cM region on chromosome8p21 in three families of Western European origin. We found no evidence for genetic heterogeneity and excluded by mutation analysis the hairless gene and nine other genes mapping in the MU interval and expressed in skin. These results provide evidence for the presence in chromosomal region 8 p21 of a gene distinct from hairless which plays a role in hair follicle biology.

Mapping the MU gene to the same locus as autosomal recessive congenital atrichia suggested the hairless gene to be a strong candidate for MU. In support of the hypothesis that the two conditions could be allelic disorders was the observation that mutations in a unique gene can cause dominant and recessive disease, the recessive phenotype being often more severe than the dominant one. ${ }^{29,30}$ However, the absence of mutations in the hairless gene and/or cDNA in the five patients studied indicates that MU and congenital atrichia are caused by mutations in distinct and closely mapped genes on chromosomal region 8p21. One can hypothesize that the MU and hairless genes may belong to a cluster of genes with related function.

During our mutation screening in the hairless gene and CDNA, we identified two rare polymorphisms (P62T and A576V) which required the testing of more than 200 controls before excluding them as being causative mutations. This suggests that the presence of rare amino-acid changes in the hairless should be thoroughly investigated in controls before assessing their significance in disease. In contrast with Cichon et al who previously reported exclusive expression of transcript lacking exon 17 in skin, ${ }^{16}$ we identified in keratinocytes in vitro, transcripts lacking exon 17, full length transcripts and transcripts harbouring an additional glutamine residue preceding exon 6 . This amino acid addition is likely to result from the use of a cryptic ag splice-acceptor site located in intron 5 three nucleotides upstream of exon 6 . The significance of these differently spliced products in cultured keratinocytes is unclear, but their presence in controls indicate that they do not result from pathogenic mutations.

With the exception of the hairless gene, the other known genes and ESTs mapping in the MU region were not obvious candidates. Of these genes, EGR3 encodes a zinc-finger transcription factor which belongs to a multigene family including Egr1 (NGFI-A), Egr2 (Krox-20) and Egr4 (NGFI-C). ${ }^{31}$ These genes are thought to regulate critical events during cellular growth and differentiation, and the recent observation that EGR3 is highly expressed in hair follicles ( $L$ Gambardella and Y Barrandon, 1999, personal communication) led us to speculate that EGR3 was a possible candidate. However, mutation screening of EGR3 mRNA by sequencing in $\mathrm{MU}$ patients remained negative, indicating that this gene is not involved in $\mathrm{MU}$. 
B1
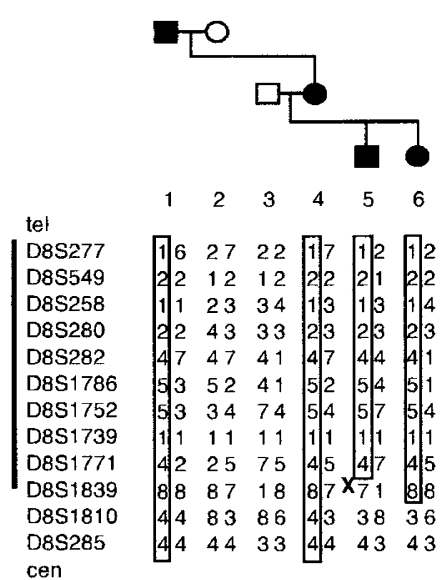

F1

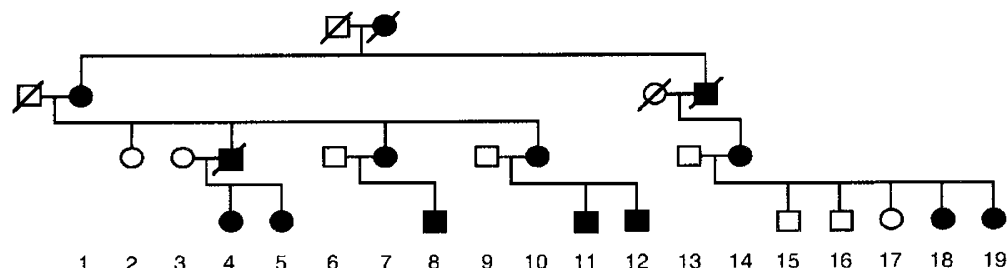

D8S549

D8S258

D8S280

D8S282

D8S 1786

D8S1752

D8S1739

D8S1839

D8S1810

D8S285

cen

F2

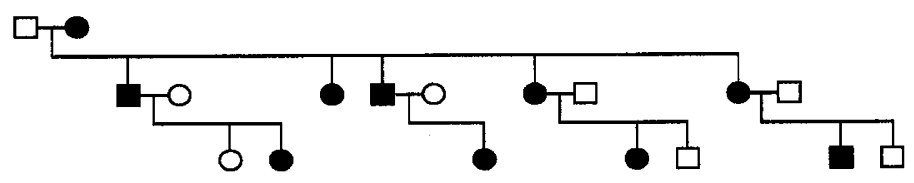

tel

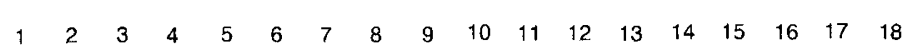

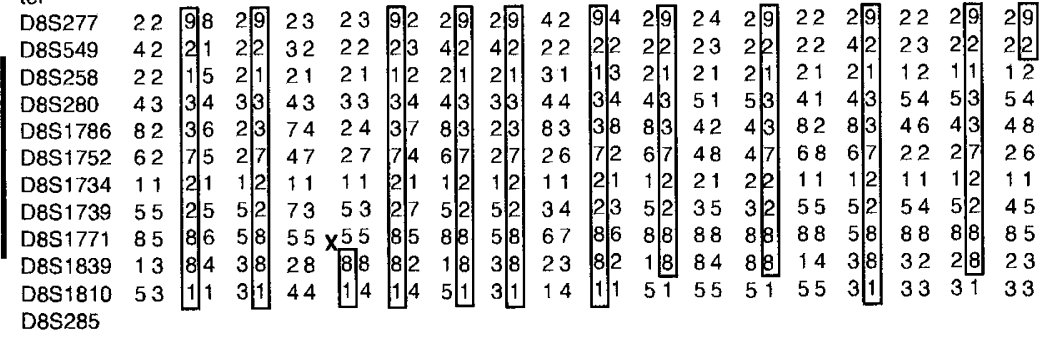

cen

Figure 2 Haplotype analysis on chromosomal region 8p21 showing critical recombinants in MU pedigrees. Solid symbols: affected individuals, open symbols: unaffected individuals. The boxed alleles are those associated with MU. The black bar on the left indicates the critical region for the disease locus. Only recombination events defining the minimal locus of MU are indicated by crosses. The cross-hatched alleles are those adjacent to crossover points, where haplotype assignment is not possible because of homozygosity in the transmitting parent. 
MU displays distinctive clinical and hair microscopy findings. ${ }^{1-6}$ In contrast with congenital atrichia in which all hair loss is complete at birth, patients with MU develop coarse and twisted hair during childhood which is gradually lost with a marked aggravation around puberty. Consistent with the finding that $\mathrm{MU}$ and congenital atrichia are not allelic disorders, these features suggest that distinct molecular mechanisms underlie the two diseases.

While this manuscript was in preparation, van Steensel and colleagues reported local isation of the MU gene to 8p21 in a Dutch and a British family, in a genetic region estimated to be 2.4 CM between D8S258 and D8S298. ${ }^{32}$ These authors also excluded by mutation analysis the hairless gene in one family, a finding which we have confirmed in five unrelated affected individuals. The identification of the MU gene will provide insights into the control of normal hair growth and structure and may help in understanding some of the distinctive clinical features of the disease.

\section{Acknowledgements}

We thank the patients and their families for participating in this study. We are grateful to Dr J Zeller, F Wojnarowska, S Burge, and M Young for referring families $F 1, B 1$, patients $B 2$ and $B 3$, respectively, to our laboratory; to A Sakuntabhai for his help in mutation detection; $S$ Compton for critical reading of the manuscript; and to S Fraitag for histological examination of skin sections. This work was supported by grants from the Dystrophic Epidermolysis Bullosa Research Association (DEBRA) of the UK to AH, and from CR INSERM 96-02 to YB. AH held a DEBRA UK fellowship.

\section{References}

1 Unna M: Über hypotrichosis congenital hereditaria. Dermatol Wochenschr 1925; 81: 1167-1178.

2 Stevanovic DV: Hereditary hypotrichosis congenita: Marie Unna type. Br J Dermatol 1970; 83: 331-337.

3 Solomon LM, Esterly NB, Medenica M: Hereditary trichodysplasia: Marie Unna's hypotrichosis. J Invest Dermatol 1971; 57: 389-400.

4 Peachey RDG, Wells RS: Hereditary hypotrichosis (Marie Unna type). Trans St Johns Hosp Dermatol Soc 1971; 57: 157-166.

5 Lalevic-Vasic BM, Polic D, Nikolic MM: Hypotrichose héréditaire de Marie-Unna. Ann Dermatol Venereol 1992; 119: 25-29.

6 Papadavid E, Dover R, Mallon E, Dawber RPR: Marie Unna hypotrichosis: an autosomal dominant hair disorder. J Eur Acad Dermatol Venereol 1996; 7: 279-283.

7 Hardy MH: The secret life of the hair follicle. Trends Genet 1992; 8 : 55-61.

8 Chiang C, Swan RZ, Grachtchouk M et al: Essential role for Sonic hedgehog during hair follicle morphogenesis. Dev Biol 1999; 205: $1-9$.

9 Millar SE, Willert K, Salinas PC et al: WNT signaling in the control of hair growth and structure. Dev Biol 1999; 207: 133-149.

10 Gat U, DasGupta R, Degenstein L, Fuchs E: De novo hair follicle morphogenesis and hair tumors in mice expressing a truncated $\beta$-catenin in skin. Cell 1999; 95: 605-614.
11 Winter $\mathrm{H}$, Rogers MA, Langbein $\mathrm{L}$ et al: Mutations in the hair cortex keratin $\mathrm{hHb} 6$ cause the inherited hair disease monilethrix. Nat Genet 1997; 16: 372-374.

12 Ahmad W, Irvine AD, Lam H et al: A missense mutation in the zinc-finger domain of the human hairless gene underlies congenital atrichia in a family of Irish travellers. Am J Hum Genet 1998; 63: 984-991.

13 Ahmad W, Faiyaz ul Haque M, Brancolini V et al: Alopecia universalis associated with a mutation in the human hairless gene. Science 1998; 279: 720-724.

14 Ahmad W, Zlotogorski A, Panteleyev AA et al: Genomic organization of the human hairless gene (HR) and identification of a mutation underlying congenital atrichia in an Arab Palestinian family. Genomics 1999; 56: 141-148.

15 Ahmad W, Nomura K, McGrath JA, Hashimoto I, Christiano AM: A homozygous nonsense mutation in the zinc-finger domain of the human hairless gene underlies congenital atrichia. J Invest Dermatol 1999; 113: 281-283.

16 Cichon S, Anker M, Vogt IR et al: Cloning, genomic organization, alternative transcripts and mutational analysis of the gene responsible for autosomal recessive universal congenital alopecia. Hum Mol Genet 1998; 7: 1671-1679.

17 Frank J, Pignata C, Panteleyev AA et al: Exposing the human nude phenotype. Nature 1999; 398: 473-474.

18 Monreal AW, Ferguson BM, Headon DJ, Street SL, Overbeek PA, Zonana J: Mutations in the human homologue of mouse dl cause autosomal recessive and dominant hypohidrotic ectodermal dysplasia. Nat Genet 1999; 22: 366-369.

19 Kere J, Srivastava AK, Montonen $O$ et al: X-linked anhidrotic (hypohidrotic) ectodermal dysplasia is caused by mutation in a novel transmembrane protein. Nat Genet 1996; 13: 409-416.

20 Chelly J, Tümer Z, Tønnesen T et al: Isolation of a candidate gene for Menkes disease that encodes a potential heavy metal binding protein. Nat Genet 1993; 3: 14-19.

21 Monk S, Sakuntabhai A, Carter SA et al: Refined genetic mapping of the Darier locus to a <1-cM region of chromosome12q24.1, and construction of a complete, high-resolution P1 artificial chromosome/bacterial artificial chromosome contig of the critical region. Am J Hum Genet 1998; 62: 890-903.

22 Lathrop GM, Lalouel JM: Easy calculations of lod scores and genetic risks on small computers. Am J Hum Genet 1984; 36: 460-465.

23 Rochat A, Kobayashi K, Barrandon Y: Location of stem cells of human hair follicles by clonal analysis. Cell 1994; 76: 1063-1073.

24 Sakuntabhai A, Burge S, Monk S, Hovnanian A: Spectrum of novel ATP2A2 mutations in patients with Darier's disease. Hum Mol Genet 1999; 8: 1611-1619.

25 Ganguly A, Rock MJ, Prockop DJ: Conformation-sensitive gel electrophoresis for rapid detection of single base differences in double stranded PCR products and DNA fragments: evidence for solvent-induced bends in DNA heteroduplexes. Proc Natl Acad Sci USA 1993; 90: 10325-10329.

26 Rogers MA, Nischt R, Korge B et al: Sequence data and chromosomal localization of human typel and typell hair keratin genes. Exp Cell Res 1995; 220: 357-362.

27 Volz A, Korge BP, Compton JG, Ziegler A, Steinert PM, Mischke D: Physical mapping of a functional cluster of epidermal differentiation genes on chromosomelq21. Genomics 1993; 18: 92-99.

28 Overhauser J, Mewar R, Rojas K, Lia K, Kline AD, Silverman GA: STS map of genes and anonymous DNA fragments on human chromosome18 using a panel of somatic cell hybrids. Genomics 1993; 15: 387-391.

29 Eber SW, Gonzalez JM, Lux ML et al: Ankyrin-1 mutations are a major cause of dominant and recessive hereditary spherocytosis. Nat Genet 1996; 13: 214-218. 
30 Christiano AM, McGrath JA, Tan KC, Uitto J: Glycine substitutions in the triple-helical region of typeVII collagen result in a spectrum of dystrophic epidermolysis bullosa phenotypes and patterns of inheritance. Am J Hum Genet 1996; 58: 671-681.

31 Patwardhan S, Gashler A, Siegel MG et al: EGR3, a novel member of the Egr family of genes encoding immediate-early transcription factors. Oncogene 1991; 6: 917-928.
32 van Steensel M, Smith FJD, Steijlen PM et al: The gene for hypotrichosis of Marie Unna maps between D8S258 and D8S298: exclusion of the hr gene by CDNA and genomic sequencing. Am J Hum Genet 1999; 65: 413-419. 